\title{
The effect of Zirconium Nitride coating on shear bond strength with denture base resin in Co-Cr alloy and titanium alloy
}

\author{
Chan Park, Kyoung-Hun Lee, Hyun-Pil Lim* \\ Department of Prosthodontics, School of Dentistry, Chonnam National University, Gwangju, Republic of Korea
}

Purpose: The purpose of this study was to evaluate of Zirconium Nitride (ZrN) coating on shear bond strength with denture base resin in Co-Cr and Ti-6Al-4V alloy. Materials and Methods: Co-Cr and Ti-6Al-4V alloy disks (10 mm in diameter, $2.5 \mathrm{~mm}$ in thickness; each other: $n=14$ ) were prepared and divided with 2 groups each other by ZrN coating. After primer was applied to disks surface, denture base resin with diameter $6 \mathrm{~mm}$, height $5 \mathrm{~mm}$ was bonded on metal disk surface. After surface roughness was measured by Profiler, shear bond strength was determined with Universal testing machine and analyzed with two-way ANOVA. The specimen surfaces and failure mode were examined using a scanning electron microscope. Results: ZrN coated groups showed significantly higher rough surface than non-coated groups $(P<0.05)$. Irrespective of alloy materials, shear bond strength of ZrN coated groups were lower than non-coated groups $(P<0.001)$. The scanning electron microscope (SEM) of ZrN coated groups showed mixed and adhesive fractures. Conclusion: ZrN coating weakened bonding strength between denture base resin and Co-Cr, Ti-6Al-4V alloy. (J Dent Rehabil Appl Sci 2016;32(3):194-201)

Key words: Zirconium Nitride (ZrN); Co-Cr alloy; Ti-6Al-4V alloy; denture base resin; shear bond strength

\section{서론}

상실된 무치악 부위를 수복하기 위한 보철물 종류는 크게 고정성과 가철성으로 분류할 수 있다. 이중 가철성 보철물은 일반적으로 금속 구조물과 레진 의치상, 인공 치아로 구성되며, 각각의 구성물들이 물리적, 화학적 결 합을 이루고 있는 양상을 보인다. 금속 구조물을 위한 재 료로는 Co-Cr 합금과, 타이타늄 합금(이하 Ti-6Al-4V 합 금) 등이 사용되고 있으며, 이는 적절한 강도 및 생체 적 합성과 레진 의치상과의 안정적인 결합력을 나타내어 현 재까지도 널리 사용되고 있다. ${ }^{1,2}$

가철성 보철물에서 금속 구조물과 레진 의치상, 혹은 인공치아와의 결합 정도가 보철물의 수명에 매우 중요 한 역할을 한다. 이러한 결합력을 증가시키기 위해 기계

*Correspondence to: Hyun-Pil Lim

Associate Professor, Department of Prosthodontics, School of Dentistry, Chonnam National University, 33 Yongbong-ro, Buk-gu, Gwangju, 61186, Republic of Korea

Tel: +82-62-530-5577, Fax: +82-62-530-5639, E-mail: mcnihil@jnu.ac.kr

Received: July 18, 2016/Last Revision: July 26, 2016/Accepted: August 3, 2016
적인 결합과 ${ }^{3}$ 금속 프라이머를 이용한 화학적인 결합 ${ }^{4-9}$ 이 이용되어 왔지만, 이를 더욱더 증가 시키기 위한 효과 적인 방법이 요구되고 있다. 또한 금속 구조물은 금속 고 유의 색상으로 인해 매우 비심미적일 수 밖에 없다. 따라 서 이러한 2 가지 문제점을 해결하기 위해 다양한 방법이 제시되어 왔는데, 그 중 한가지 방법이 Titanium Nitride (TiN)와 Zirconium Nitride $(\mathrm{ZrN})$ 와 같은 질화물 코팅 기술이다. 질화물 코팅 기술은 우선 금속 구조물을 금 빛이 띄게 함으로써 심미적 개선을 이룰 수 있다. ${ }^{10-12}$ 또 한 질화물 코팅 기술은 기계적 성질 역시 증가시킬 수 있 다. ${ }^{13-15} \mathrm{TiN}$ 코팅의 교정용 선재에 적용 시 부식 및 마찰 저항성을 증진 시킬 수 있고, ${ }^{16-18}$ 또한 $\mathrm{TiN}$ 코팅이 고온에 서 타이타늄의 산화를 어렵게 하여 도재와의 결합을 증 진 시킬 수 있다는 보고도 있다. ${ }^{13}$ 뿐만 아니라 질화물 코

Copyright@ 2016 The Korean Academy of Stomatognathic Function and Occlusion. (c) It is identical to Creative Commons Non-Commercial License. 
팅은 항 세균성 효과를 얻을 수 있으며, 이는 임플란트 지 대주에 이미 널리 사용되고 있는 실정이다. ${ }^{19}$ 그러나 이러 한 질화물 코팅 기술을 가철성 의치의 금속 구조물에 적 용한 연구는 아직 그 자료가 부족한 실정이다.

본 연구의 목적은 가철성 의치에 주로 사용되는 2가지 금속인 $\mathrm{Co}-\mathrm{Cr}$ 합금과 $\mathrm{Ti}-6 \mathrm{Al}-4 \mathrm{~V}$ 합금에 $\mathrm{ZrN}$ 코팅을 적 용하였을 때, 의치상 레진과의 결합력에 어떠한 영향을 미치는지 비교 분석하는 것이다. 본 실험은 $\mathrm{ZrN}$ 코팅이 2 가지 합금과 의치상 레진의 결합력에 영향을 미치지 않 는다는 귀무가설 하에 수행하였다.

\section{연구 재료 및 방법}

\section{1. 금속 시편 제작}

2가지 금속 합금인 Co-Cr 합금(Biosil F, Degussa Co, Hanau, Germany)과 Ti-6Al-4V 합금(Ti-6Al-4V ASTM Grade V, Kobe steel Co., Kobe, Japan)을 직경 $10 \mathrm{~mm}$, 높이 $2.5 \mathrm{~mm}$ 의 디스크 형태로 각각 14 개씩 제작하였다.

\section{2. 질화물 코팅 표면처리}

모든 금속 시편은 No. $600 \mathrm{SiC}$ abrasive paper (Waterproof Abrasive Paper cw-600, Daesung Abrasive Co., Seoul, Korea)를 이용하여 연마하였고, 아세톤, 에
틸알코올, 증류수에서 각각 10 분씩 초음파 세척을 하였 다. 시편 건조 후에, $\mathrm{ZrN}$ 코팅은 AIP (arc ion plating) 공법 다목적 코팅 시스템(ATS-MC-STD-300 ${ }^{\circledR}$, A-tech system, Seoul, Korea)으로 공정 압력 $7.5 \mathrm{mTorr}, 300^{\circ} \mathrm{C}$ 에서 N2유량 $300 \mathrm{scm}$ 을 유입하여 바이어스 $-30 \mathrm{~V}$, 아크 전류 $65 \mathrm{~A}$ 로 설정하여 약 2 시간 동안 증착 코팅을 시행 하였다. 시편의 종류와 표면처리의 유무에 따라 총 4 개의 그룹으로 분류하였고, 이는 Table 1에서 제시하고 있다.

\section{3. 레진 접착}

금속 시편에 의치상 레진을 부착시키기 위해 실리콘 주형을 이용하여 일정한 크기(직경 $6 \mathrm{~mm}$, 높이 $5 \mathrm{~mm}$ ) 의 왁스 패턴을 만든 후, 시편의 중앙에 위치시켰다. (Fig. 1A, 1B) 그 후, 레진 의치상을 만드는 통상적인 방 법에 의거하여 석고에 매몰하고 소환하였다. 소환된 왁 스를 완전하게 제거한 뒤에, 모든 그룹의 시편 표면에

Table 1. Experimental groups of specimens used in this study

\begin{tabular}{cccc}
\hline Groups & Metal alloy & Coating & $\mathrm{n}$ \\
\hline C & Cobalt-Chrome alloy & - & 7 \\
CZ & Cobalt-Chrome alloy & ZrN & 7 \\
T & Ti-6Al-4V alloy & - & 7 \\
TZ & Ti-6Al-4V alloy & ZrN & 7 \\
\hline
\end{tabular}

A

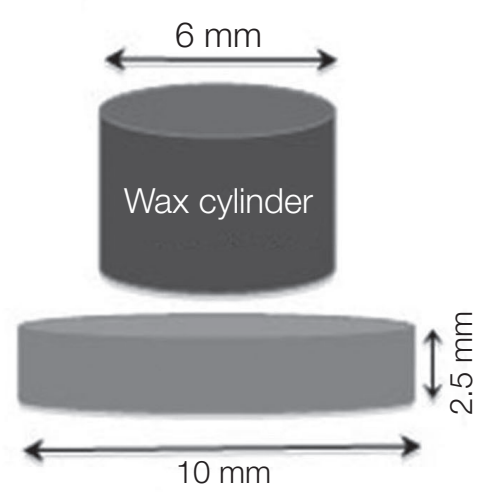

B

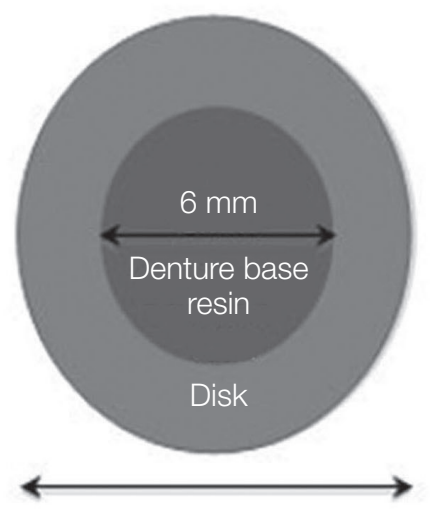

C

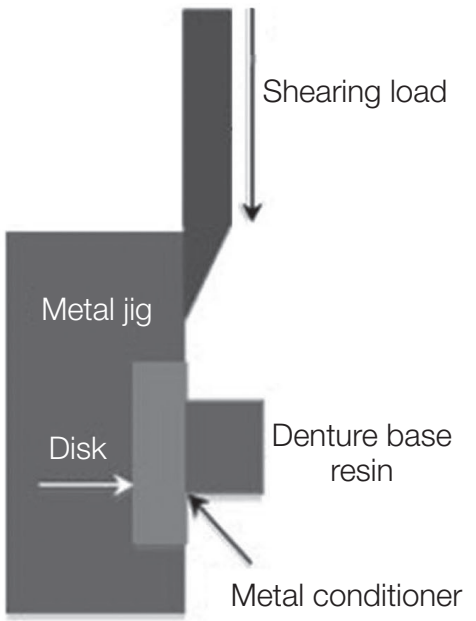

Fig. 1. Schematic diagrams of (A) the wax cylinder and disk, (B) the denture base resin on the disk, and (C) the shear bond strength test. 
metal conditioner (Alloy Primer, Kuraray Medical Inc., Okayama, Japan)를 제조사의 지시에 따라 적용하고 건 조시켰다. 그 후, 열중합형 의치상 레진(QC-20 Denture Base, Dentsply International Inc., Chicago, USA)을 제 조사의 지시에 따라 혼합 후 소환된 왁스 패턴 자리에 전입하였고, 이를 수동 유압기를 이용하여 충분한 압력 으로 가압하였다. 가압된 레진은 제조사의 지시에 따라 Heat curing unit (SEKI Dental Co., Seoul, Korea)에서 $74^{\circ} \mathrm{C}$ 물에서 9시간 동안 열 중합 하였다.

\section{4. 전단결합강도 측정}

금속 시편이 정확히 안착될 수 있는 금속 지그를 이 용하여 시편을 고정시킨 후, 전단결합강도를 측정하였 다(Fig. 1C). 전단결합강도는 만능 시험기(Model 1125, Instron, Canton, USA)를 이용하여, Crosshead 속도 를 $1.0 \mathrm{~mm} / \mathrm{min}$ 으로 설정하여, 최대 파절 하중치를 기 록하였다. 그 후, 파절된 표면은 주사전자현미경(FESEM, JSM-7500F, JEOL, Tokyo, Japan)을 이용하여 관 찰하였고(200배 또는 500배), 이는 부착성 파절(adhesive failure), 응집성 파절(cohesive failure), 혼합성 파절 (mixed failure)로 구분하였다.

\section{5. 표면 거칠기 측정}

표면의 거칠기 정도는 표면 측정기(DIAVITE DH-7, Asmeto AG, Bachenbülach, Switzerland)를 이용하여 각 시편당 세 부분을 무작위로 선정하여 측정하였다.

\section{6. 통계분석}

모든 군의 전단결합강도는 정규 분포를 따랐으며, 시 편의 재료와 $\mathrm{ZrN}$ 코팅 처리에 따른 전단결합강도의 차 이를 검정하기 위해 이원분산분석(two-way ANOVA) 으로 분석하였다 $(\alpha=0.05) . \mathrm{ZrN}$ 코팅 처리에 따른 거 칠기의 차이를 검정하기 위해 $\mathrm{t}$-검정(t-test)을 시행하였 다. 통계 분석은 SPSS (SPSS 20.0, IBM Corp., Armonk, USA)를 사용하였다.

\section{결과}

각 군의 전단결합강도 평균 및 표준 편차는 Table 2에서 보여주고 있다. C군에서 전단결합강도가 가장 높게 나타 났고, CZ군의 전단결합강도가 가장 낮게 나타났다. Twoway ANOVA로 검정한 결과, 재료 간의 전단결합강도 차 이는 유의하지 않았고 $(P>0.05)$, 코팅 유무에 따른 전단 결합강도는 유의한 차이가 있었다 $(P<0.001$, Table 3$)$.

Table 2. Mean shear bonding strength $(\mathrm{MPa})$ for experimental groups

\begin{tabular}{ccccc}
\hline Group & Metal alloy & Coating & $\mathrm{n}$ & Mean \pm SD \\
\hline C & Cobalt-Chrome & - & 7 & $16.54 \pm 4.10$ \\
CZ & Cobalt-Chrome & ZrN & 7 & $6.29 \pm 2.07$ \\
T & Ti-6Al-4V & - & 7 & $17.97 \pm 7.03$ \\
TZ & Ti-6Al-4V & ZrN & 7 & $6.66 \pm 2.98$ \\
\hline
\end{tabular}

Table 3. The result of two-way ANOVA on shear bond strength

\begin{tabular}{crrrrr}
\hline Source & Type III sum of square & df & Mean square & F & Sig. \\
\hline Metal & 5.670 & 1 & 5.670 & .286 & $.598^{*}$ \\
Coating & 814.321 & 1 & 814.321 & 41.043 & $.000^{* *}$ \\
Metal $*$ Coating & 1.956 & 1 & 1.956 & .099 & .756 \\
\hline
\end{tabular}

Sig., significance.

*, $P>0.05$;**, $P<0.001$. 
Fig. 2, 3에서는 각각의 시편에 대한 표면을 scanning electron microscope (SEM) 사진으로 보여주고 있다. C 군과 $\mathrm{T}$ 군은 연마된 표면을 보여주고 있으며, CZ군과 TZ 군은 $\mathrm{AIP}$ 공법을 이용한 $\mathrm{ZrN}$ 코팅의 전형적인 droplet을 볼 수 있다. ${ }^{7}$

Fig. 4에서는 C군과 CZ군 시편의 의치상 레진의 파절 양상을 SEM 사진으로 나타내고 있다. C군 시편에서는 혼합성 파절양상을 보였고, $\mathrm{CZ}$ 군 시편에서는 부착성 파 절과 혼합성 파절양상이 함께 관찰되었으며, 혼합성 파

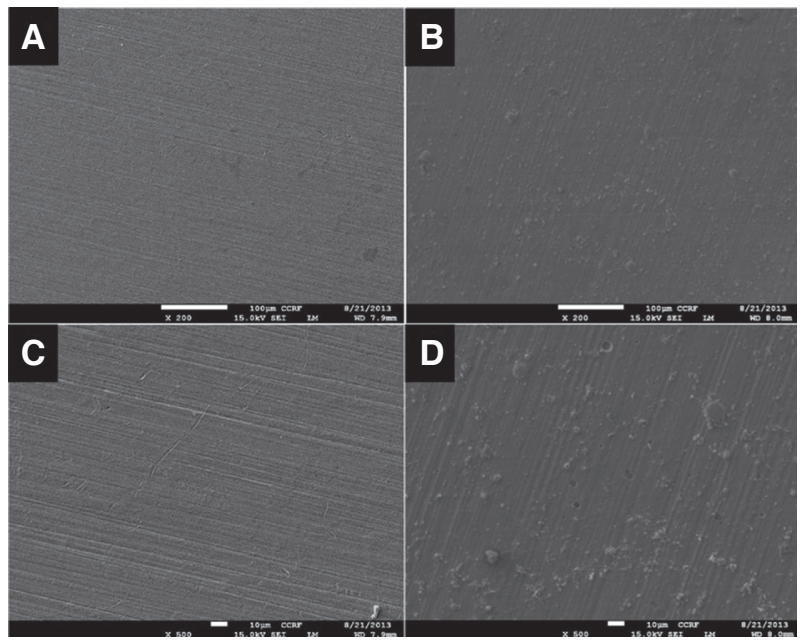

Fig. 2. SEM micrographs of the Co-Cr surface (group C) and ZrN coating surface (group CZ). A) group C ( $\times 200)$, $B)$ group $C(\times 500)$, C) group $C Z(\times 200)$, D) group $C Z$ $(\times 500)$.

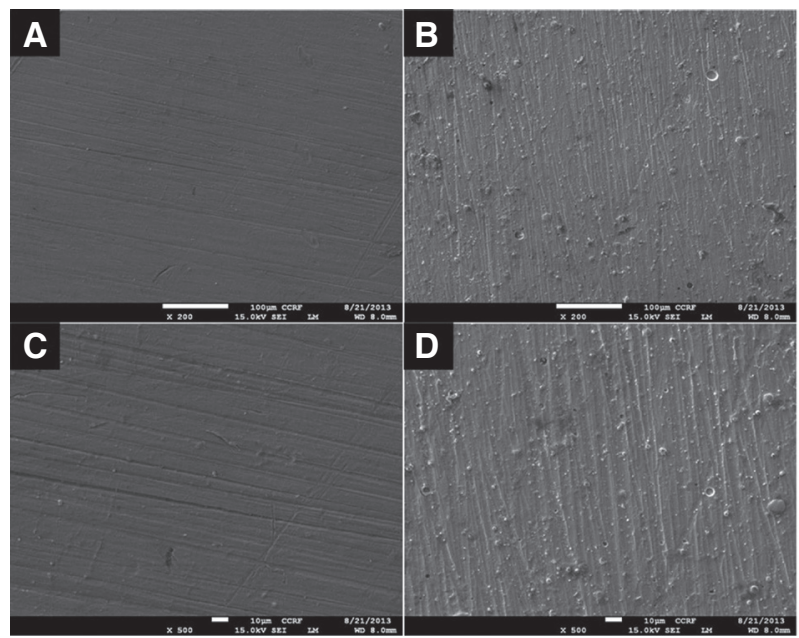

Fig. 3. SEM micrographs of the Ti surface (group T) and ZrN coating surface (group TZ). A) group $T(\times 200), B)$ group $T(\times 500), C)$ group TZ $(\times 200)$, D) group TZ $(\times 500)$.
절양상들과의 비교 시 $\mathrm{C}$ 군에서 상대적으로 더 많은 의치 상 레진이 남아있었다. Fig. 5 는 T군과 TZ군 시편의 의치 상 레진의 파절 양상을 보여주고 있다. Ti-6Al-4V 합금 시편도 Fig. 4의 Co-Cr 합금 시편과 비슷한 양상으로 TZ 군 시편에서는 부착성 파절와 혼합성 파절, $\mathrm{T}$ 군 시편에서 는 혼합성 파절 만을 나타내었고, $\mathrm{T}$ 군이 상대적으로 더 많은 의치상 레진이 금속 시편에 남아있었다.

t-test로 검정한 표면 거칠기 $(\mathrm{Ra})$ 는 $\mathrm{C}$ 군보다 $\mathrm{CZ}$ 군에 서 통계적으로 유의하게 더 큰 거칠기 값을 보였고 $(P<$ 0.05), $\mathrm{T}$ 군보다 $\mathrm{TZ}$ 군에서 통계적으로 유의하게 보다 큰 거칠기 값을 나타내었다 $(P<0.001$, Table 4).

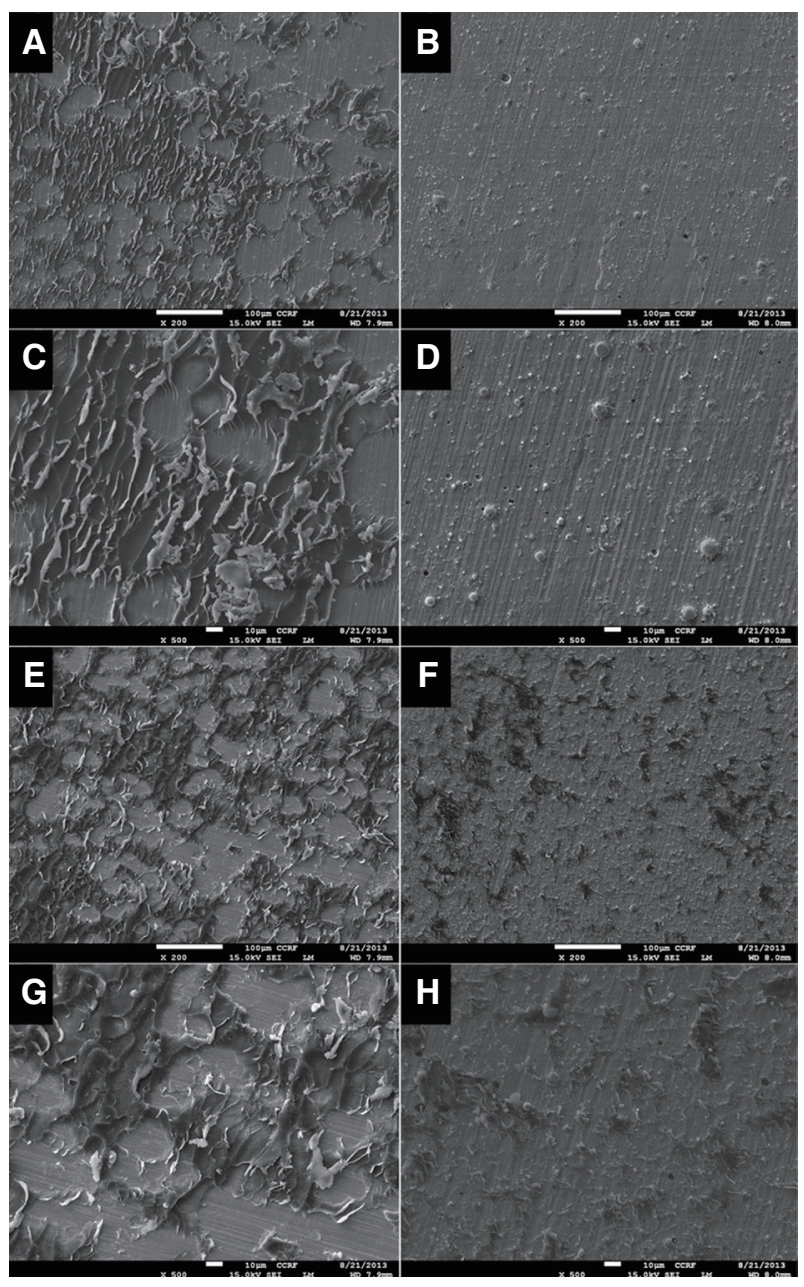

Fig. 4. SEM photomicrographs $\mathrm{Co}-\mathrm{Cr}$ alloy specimens after shear bonding stress test. (A) group $\mathrm{C}$ mixed fracture $(\times 200)$, (B) group C mixed fracture $(\times 500)$, (C) group $C$ mixed fracture $(\times 200)$, (D) group C mixed fracture $(\times 500)$, (E) group CZ adhesive fracture $(\times 200)$, (F) group CZ adhesive fracture $(\times 500)$, (G) group CZ mixed fracture $(\times 200)$, $(H)$ group $C Z$ mixed fracture $(\times 500)$. 


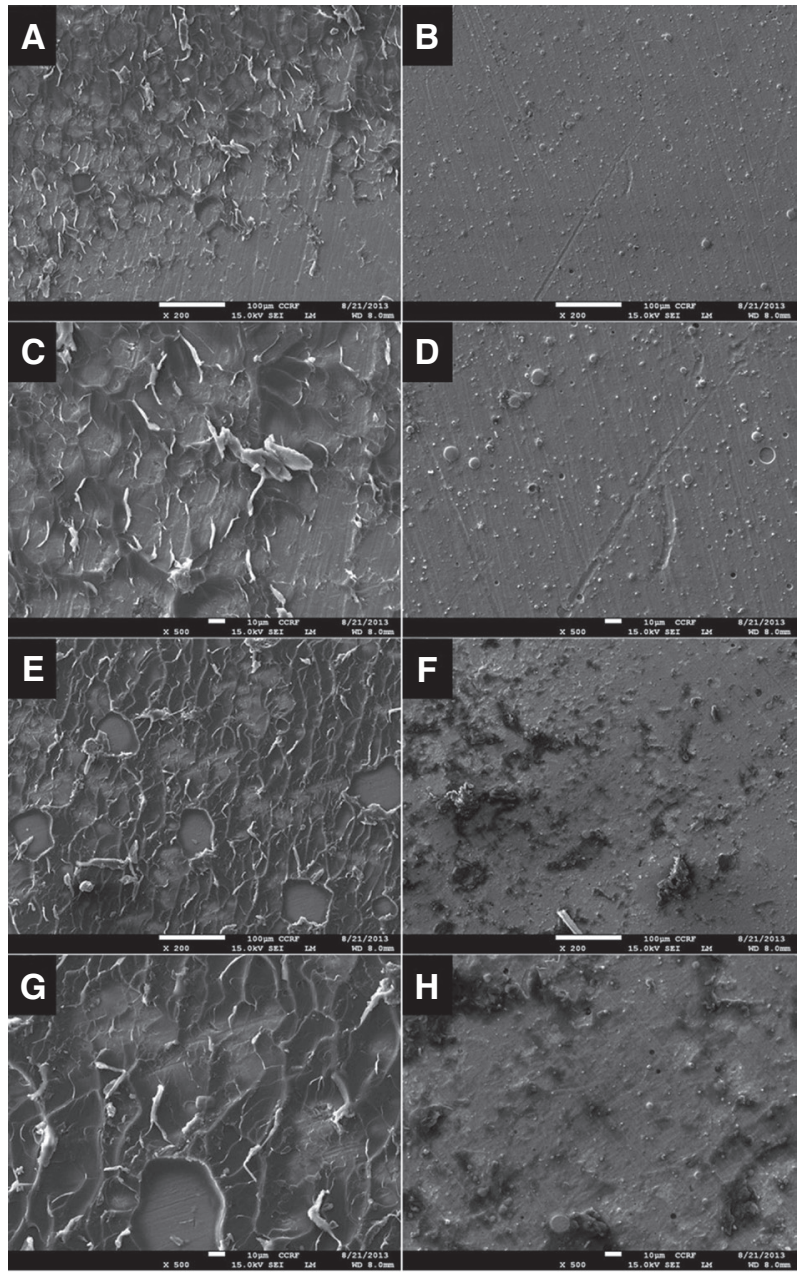

Fig. 5. SEM photomicrographs Ti-6Al-4V specimens after shear bonding stress test. (A) group $T$ mixed fracture $(\times 200)$, (B) group $T$ mixed fracture $(\times 500)$, (C) group $T$ mixed fracture $(\times 200)$, (D) group $T$ mixed fracture $(\times 500)$, (E) group TZ adhesive fracture $(\times 200),(F)$ group TZ adhesive fracture $(\times 500)$, $(G)$ group TZ mixed fracture $(\times 200),(H)$ group TZ mixed fracture $(\times 500)$.

\section{고찰}

본 연구는 $\mathrm{ZrN}$ 코팅이 2 가지 합금과 의치상 레진의 결 합력에 영향을 미치지 않는다는 귀무가설 하에 수행 되 었다. Co-Cr 합금과 Ti-6Al-4V 합금을 디스크 형태로 만 들어 이를 $\mathrm{ZrN}$ 코팅한 그룹과 그렇지 않은 그룹으로 구 분한 뒤, 통상적인 방법으로 왁스 패턴의 매몰과 소환 과 정을 거친 의치상 레진을 합금과 결합시켰다. 만능시험기 와 SEM 사진을 활용하여 전단결합강도와 파절 양상을 관찰하였다. 실험의 결과는 시편의 종류와 상관없이 $\mathrm{ZrN}$ 코팅된 시편이 그렇지 않은 시편에 비해 유의하게 낮은 전단결합강도를 보였으며, 따라서 본 연구의 귀무 가설 은 기각되었다.

$\mathrm{TiN}$ 또는 $\mathrm{ZrN}$ 코팅 방법은 금속 재료공학 분야에서 공구나 금형의 내구성을 향상 시킬 목적으로 이미 널리 이용되고 있으며, 치과 재료 분야에서도 많은 시도가 이 루어 지고 있다. ${ }^{8,9}$ 특히 $\mathrm{ZrN}$ 은 TiN에 비해 광택이 우수 하며, 내구성도 증가시켜 임플란트 지대주에 이미 널리 사용되고 있다. ${ }^{12}$ 그러나, 임플란트의 지대주 외에 치과재 료에서는 사용이 제한된 상태이며, 특히 금속 구조물을 필수로 하는 가철성 보철물상에서의 질화물 코팅 기술은 그 연구가 아직 미비한 실정이다. 본 실험은 이미 알려진 $\mathrm{ZrN}$ 코팅의 심미적, 기계적 효과를 가철성 의치 금속구 조물에 적용하고자 하는 것에서 출발되었고, 이때 코팅 된 금속 구조물과 의치상 레진의 결합력은 보철물의 수 명 및 활용도에 가장 중요하다고 판단되었기 때문에 이 부분에 초점을 맞추어 실험을 진행하였다.

현재 국소의치 금속구조물의 재료로 가장 많이 사용 되는 재료는 $\mathrm{Co}-\mathrm{Cr}$ 합금이다. Ti-6Al-4V 합금의 경우 과 거에는 제작 시 높은 실패율로 인해 사용에 제한이 있었 으나, 현재는 주조 기술의 발전으로 인해 최근에 각광받 고 있다. ${ }^{2}$ 따라서 이러한 2 가지 금속 시편을 이용하여 실

Table 4. The result of t-test on surface roughness

\begin{tabular}{ccccc}
\hline Group & $\mathrm{n}$ & Mean roughness $(\mu \mathrm{m})$ & Standard deviation $(\mu \mathrm{m})$ & Sig. \\
\hline $\mathrm{C}$ & 7 & .1476 & .03376 & $.002^{*}$ \\
$\mathrm{CZ}$ & 7 & .2467 & .05725 & .01997 \\
$\mathrm{~T}$ & 7 & .1476 & .03463 & $.000^{* *}$ \\
$\mathrm{TZ}$ & 7 & .2248 & .03 & \\
\hline
\end{tabular}

Sig., significanse.

$*, P>0.05 ; * *, P<0.001$ 
험을 진행하였다. 왁스 패턴의 매몰 및 소환 과정에 오는 임상적 효과를 동일하게 적용되게 하여 실제 임상에서의 활용도를 판단하기 위해, 금속 시편상에서 의치상 레진 의 적용방법은 실제 가철성 보철물의 제작과정과 동일하 게 진행하였다.

실험 결과는 $\mathrm{ZrN}$ 으로 코팅한 군이 코팅하지 않은 군 보다 통계적으로 유의하게 약한 전단결합강도를 보였다. 이는 SEM 사진에서도 뚜렷하게 확인할 수 있었다. 표면 거칠기 측정 결과는 $\mathrm{ZrN}$ 코팅이 더 거친 표면을 만들어 냄을 보여주었다. 일반적으로 표면의 거칠기를 증가시키 면 표면적이 증가하여 기계적인 결합력이 증가됨을 예상 할 수 있다. 현재 임상에서 가철성 의치의 금속 구조물과 의치상 레진의 기계적인 결합력을 증가시키기 위한 방법 으로는 플라스틱-망사형 납형(plastic mesh pattern) 혹 은 격자구조(open framework)로 금속 구조물을 디자인 하고 있다. 그러나 본 실험에서는 거친 표면의 질화물 코 팅 시편이 오히려 낮은 결합력을 보임으로써, 시편의 표 면 거칠기는 그 영향력이 미미한 것으로 확인되었다. 따 라서 본 실험 디자인 상에서의 결합력은 기계적인 결합 보다 금속 프라이머의 화학적인 결합이 더 크게 작용했 다고 판단된다. 이 연구에서 사용된 금속 프라이머는 MDP(10-methacryloyloxydecyl dehydrogen phosphate) 와 VBATDT(6-(4-vinylbenzyl -n-propyl) amino-1,3,5,triazine-2,4-dithione monomer)성분이 포함되어 있다고 알려져 있다. MDP는 금속산화물과 강한 결합을 하고, VBATDT는 귀금속 합금과 MMA-PMMA-TBBO 레진 간의 결합 내구성을 증진시킨다고 보고되고 있다. ${ }^{20}$ 치과 영역에서 금속 구조물과 도재, 혹은 레진의 화학적인 결 합력은 안정적인 금속 산화물의 형성과 관련이 있다. ${ }^{21}$ 이 러한 금속 산화물이 형성되면 $\mathrm{MDP}$ 등의 화학적 성분이 이와 반응하여 결합력을 증가시키는 기전이 진행되는데, 이 실험에서 사용된 $\mathrm{ZrN}$ 코팅은 이러한 기전을 차단한 것으로 생각된다. 기존의 연구에서 TiN 코팅이 타이타늄 합금의 산화를 막는다는 보고가 있으며, ${ }^{13} \mathrm{ZrN}$ 코팅시 $\mathrm{Co}-\mathrm{Cr}$ 합금 혹은 타이타늄 합금의 산화 억제도 비슷한 과정으로 진행될 것 추측된다.

본 실험은 가철성 보철물의 기계적인 유지력을 증가 시킬 수 있는 여러 디자인을 적용하지 않고 진행하였으 며, 또한 다양한 의치상용 레진을 사용하지 않은 것이 한 계점으로 생각된다. 그러나 심미성 개선과 내구성의 증진 을 얻을 수 있는 $\mathrm{ZrN}$ 코팅이 가철성 의치 금속구조물과 의치상용 레진과의 전단결합강도를 낮출 수 있다는 본
연구의 결과는 중요한 발견으로 사료된다. $\mathrm{ZrN}$ 코팅을 임상적으로 활용하기 위해서는 앞으로 다양한 추가 연구 가 필요할 것으로 생각된다.

\section{결론}

본 실험은 $\mathrm{Co}-\mathrm{Cr}$ 합금과 $\mathrm{Ti}-6 \mathrm{Al}-4 \mathrm{~V}$ 합금에 적용한 $\mathrm{ZrN}$ 코팅이 의치상 레진과의 결합에 미치는 영향을 알 아보고자 시행되었고 다음의 결과를 얻었다.

1. $\mathrm{ZrN}$ 코팅은 금속의 재료와 상관없이 통계적으로 유의하게 표면 거칠기를 증가하였다(Co-Cr 합금, $P$ $<0.05$; Ti-6Al-4V 합금, $P<0.001)$.

2. 금속 시편의 재료에 관계없이 $\mathrm{ZrN}$ 코팅한 그룹에 서 전단결합강도가 낮았다 $(P<0.001)$.

3. 재료간의 전단결합강도 차이는 통계적으로 유의 하지 않았으나 $(P>0.05)$, 코팅 유무에 따른 전단 결합강도는 통계적으로 유의한 차이가 있었다 $(P<$ 0.001).

4. 주사전자현미경상 파절 양상에서 금속 시편 재료에 관계없이 $\mathrm{ZrN}$ 코팅하지 않은 시편에서는 혼합성 파절의 양상이 나타났고, $\mathrm{ZrN}$ 코팅 시편에서는 혼 합성 파절과 부착성 파절이 함께 나타났다.

\section{ORCID}

Chan Park http://orcid.org/0000-0002-7587-5608

Kyoung-Hun Lee http://orcid.org/0000-0003-3685-2187

Hyun-Pil Lee http://orcid.org/0000-0001-5586-1404

\section{References}

1. Rodrigues RC, Macedo AP, de Torres EM, de Mattos Mda G, Ribeiro RF. Retention force of T-bar clasps for titanium and cobalt-chromium removable partial dentures. Braz Dent J 2008;19:209-13.

2. Pierce LH, Goodkind RJ. A status report of possible risks of base metal alloys and their components. J Prosthet Dent 1989;62:234-8.

3. May KB, Van Putten MC, Bow DA, Lang BR. 4-META polymethyl methacrylate shear bond strength to titanium. Oper Dent 1997;22:37-40.

4. Brown DT, Desjardins RP, Chao EY. Fatigue failure in acrylic resin retaining minor connectors. J Pros- 
thet Dent 1987;58:329-35.

5. Dunny JA, King GE. Minor connector designs for anterior acrylic resin bases: a preliminary study. J Prosthet Dent 1975;34:496-502.

6. Jacobson TE. The significance of adhesive denture base resin. Int J Prosthodont 1989;2:163-72.

7. Jacobson TE, Chang JC, Keri PP, Watanabe LG. Bond strength of 4-META acrylic resin denture base to cobalt chromium alloy. J Prosthet Dent 1988;60:570-6.

8. Kim SS, Vang MS, Yang HS, Park SW, Lim HP. Effect of adhesive primers on bonding strength of heat cure denture base resin to cast titanium and cobalt-chromium alloy. J Adv Prosthodont 2009;1: 41-6.

9. Kawano F, Miyamoto M, Tada N, Matsumoto N. Reinforcement of acrylic resin denture base with a Ni-Cr alloy plate. Int J Prosthodont 1990;3:484-8.

10. Buth K. Gold-colored titanium nitride coating of non-precious metal adhesive bridge. Dent Labor (Munch) 1991;39:491-2.

11. Wirz J. "Gold coloring" of denture bases with titanium nitride. Quintessenz 1989;40:2285-94.

12. Laetzsch E, Blank K, Lunk A, Möller E, Pilgrim H. Gold-colored metal surface film in prosthetic treatment-preclinical studies. Stomatol DDR 1986;36: 269-72.

13. Habig KH. Friction and wear of sliding couples coated with TiC, TiN or TiB2. Surf Coat Technol 1990;42:133-147.
14. Al Jabbari YS. Physico-mechanical properties and prosthodontic applications of Co-Cr dental alloys: a review of the literature. J Adv Prosthodont 2014; 6:138-145.

15. Endo K, Sachdeva R, Araki Y, Ohno H. Effects of titanium nitride coatings on surface and corrosion characteristics of Ni-Ti alloy. Dent Mater J 1994;13: 228-39.

16. Oshida Y, Fung LW, Isikbay SC. Titanium-porcelain system. Part II: bond strength of fired porcelain on nitrided pure titanium. Biomed Mater Eng 1997;7: $13-34$.

17. Budke E, Krempel-Hesse J, Maidhof H, Schüssler H. Decorative hard coatings with improved corrosion resistance. Surf Coat Technol 1999;112:10813.

18. Du J, Zhang P, Cai Z, Zhao J. The influence of substrate-target orientation on the properties of $\mathrm{ZrN}$ films deposited by arc ion plating. Physics Procedia 2011;18:181-6.

19. Lai CH, Chang YY, Huang HL, Kao HY. Characterization and antibacterial performance of $\mathrm{ZrCN} /$ amorphous carbon coatings deposited on titanium implants. Thin Solid Films 2011;520:1525-31.

20. Kojima K, Kadoma Y, Imai Y. Adhesion to precious metals utilizing triazine dithione derivative monomer. J Jpn Dent Mater 1987;6:702-7.

21. Naylor WP, Kessler J, King A. Introduction to metal ceramic technology. Chicago; Quintessence Publishing Co; 1992. p. 27-113. 


\section{질화 지르코늄 코팅이 코발트 크롬 합금과 타이타늄 합금에서 의치상 레진과의 전 단결합강도에 미치는 영향}

\section{박 찬, 이경훈, 임현필*}

전남대학교 치의학전문대학원 보철학교실

목적: 본 연구는 Co-Cr, Ti-6Al-4V 합금에 Zirconium Nitride (이하 $\mathrm{ZrN}$ ) 적용 시, 의치상 레진과의 접착력을 비교하는 것이다.

연구 재료 및 방법: Co-Cr, Ti-6Al-4V 디스크(직경 $10 \mathrm{~mm}$, 두께 $2.5 \mathrm{~mm}$ )를 각각 14개씩 제작하였고, $\mathrm{ZrN}$ 코팅에 따라 2 개의 그룹으로 나누었다. Primer로 시편 전처리 후, 의치상 레진(직경 $6 \mathrm{~mm}$, 두께 $5 \mathrm{~mm}$ )을 부착하였다. 표면 측정기를 이용하여 시편의 거칠기를 측정한 후, 만능 시험기를 이용하여 전단결합강도를 측정하였으며, 이원분산분석으로 통계 분 석하였다. 시편 표면과 파절 양상을 주사전자현미경을 이용하여 관찰하였다.

결과: $\mathrm{ZrN}$ 을 코팅한 시편에서 유의하게 높은 표면 거칠기를 나타내었고 $(P<0.05)$, 전단결합강도는 낮았다 $(P<0.001)$. $\mathrm{ZrN}$ 코팅 시편에서는 혼합성 파절과 부착성 파절이 함께 나타났다.

결론: Co-Cr, Ti-6Al-4V 합금에서 $\mathrm{ZrN}$ 코팅 처리는 의치상 레진과의 결합력을 약화시켰다.

(구강회복응용과학지 2016;32(3):194-201)

주요어: 질화 지르코늄( $\mathrm{ZrN})$; 코발트-크롬 합금; Ti-6Al-4V 합금; 의치상 레진; 전단결합강도 